\title{
Crenças sobre o uso do material didático no ensino de línguas estrangeiras
}

\author{
Emanuele Coimbra Padilha \\ Universidade Federal de Santa Maria/UFSM \\ Caroline Mitidieri Selvero \\ Universidade Federal de Santa Maria/UFSM
}

\begin{abstract}
Resumo
Este trabalho tem por objetivo refletir sobre o uso do material didático no ensino de línguas estrangeiras. Para isso, será realizado um levantamento das crenças de alunos e professores sobre material didático encontradas, em três dissertações de mestrado. Posteriormente, nos resultados de pesquisa, serão discutidas as crenças encontradas nas dissertações.
\end{abstract}

Palavras chave: crenças de alunos e professores, material didático, ensino de língua estrangeira.

\begin{abstract}
This paper reflects on the use of didactic material in the teaching of foreign languages. A survey is conducted using three dissertations that present the beliefs of students and teachers concerning didactic material. Subsequently, the research results discuss the beliefs found in the dissertations.
\end{abstract}

Keywords: beliefs of students and teachers, didactic material, teaching foreign language.

\section{INTRODUÇÃO}

$\mathrm{Na}$ atualidade, o estudo das crenças no processo de ensino/aprendizagem de línguas tem despertado o interesse de vários pesquisadores. Sua importância no ensino passou a ser considerada como determinante a partir do surgimento da abordagem comunicativa, que se caracteriza por considerar os interesses e as experiências dos alunos como fatores que exercem papel ativo e decisivo na aprendizagem de línguas estrangeiras. As crenças podem ser definidas como tudo aquilo em que se crê. Assim, as crenças são elaboradas através das experiências vividas, podendo ser (re) construídas e influenciadas a cada nova experiência, pois fazem parte da história de vida do sujeito. Elas podem ser de um indivíduo ou de um grupo de indivíduos, e são sempre resultado 
da interação, da convivência e da vivência que cada pessoa mantém no decorrer da vida, ou seja, essas crenças podem surgir ou serem influenciadas pela interação com outras pessoas e pelo ambiente.

Nessa perspectiva, além das crenças, outro elemento que exerce forte influência para o êxito do processo de ensino/aprendizagem em língua estrangeira é o material didático utilizado, o qual pode ser definido como qualquer material que possa auxiliar nesse processo, como vídeos, áudios, DVDs, livros didáticos, apostilas, entre outros. Além disso, "os materiais didáticos devem contribuir de formas variadas para que a aprendizagem seja bem-sucedida e, se possível, rápida, prazerosa e significativa" (VILAÇA, 2009, p.07). Nesse sentido, o material didático deve ser significativo para o aluno, pois ele ocupa as funções de apresentador de conteúdos, fonte de atividade para a prática e interação comunicativa entre os estudantes e o professor.

Assim, este trabalho tem por objetivo refletir sobre o uso do material didático no ensino de línguas estrangeiras, a partir de crenças levantadas em três dissertações de mestrado, sobre o estudo de crenças de alunos e professores.

\section{CRENÇAS NO ENSINO/APRENDIZAGEM DE LÍNGUAS ESTRANGEIRAS}

As crenças sobre a aprendizagem de línguas possuem papel essencial para todo o ser humano porque influenciam na maneira de ensinar e de aprender língua estrangeira (VIANA; CARAZZAI, 2010).

O conceito de crenças é definido, frequentemente, sem um fundamento científico, relacionado a religiões, mitos, entre outros, considerado como suposições implícitas e baseadas em opiniões, tradições e costumes, teorias que podem ser discutidas e alteradas em função de novas experiências (COELHO, 2005). As crenças são consideradas, pela comunidade em geral, como opiniões pessoais ou ideias que o indivíduo possui sobre ensino/aprendizagem de uma nova língua, tendo como embasamento o conhecimento empírico, não científico, desconsiderando as pesquisas relacionadas ao assunto.

Neste trabalho, segue-se o conceito de crenças definido por Barcelos (2001). Para essa autora, crenças são ideias e opiniões que professores e alunos possuem com relação ao processo de ensino/aprendizagem.

No Brasil, a pesquisa científica sobre crenças pode ser dividida em três momentos: de 1990 a 1995; de 1996 a 2000, o período de desenvolvimento e 
consolidação das crenças; e o iniciado em 2002 e que se estende até os dias de hoje, que é o de expansão do estudo e da pesquisa em crenças (BARCELOS, 2007).

$\mathrm{Na}$ década de 80, surgiu a definição do termo crenças relacionado com a aprendizagem de línguas para tratar sobre a influência que elas exercem na experiência de aprender línguas (SILVA, 2007). Assim, as crenças seriam as formas de estudar e se preparar para o uso da língua-alvo, típicas de determinada etnia, região, classe social e grupo familiar, transmitidas de forma naturalizada ou implícita (ALMEIDA FILHO, 2002).

O interesse, nesse primeiro momento, era incluir as crenças dos alunos e avaliálas, porém, elas acabaram sendo consideradas equivocadas e os alunos recriminados por possuí-las. O segundo momento de estudo das crenças está relacionado, particularmente, à classificação dos tipos de crenças e a seu conceito como um conhecimento metacognitivo. Para Barcelos (2004), esse conhecimento metacognitivo era considerado falível e situado dentro da mente dos aprendizes, ou seja, pessoal e armazenado a partir de experiências que se tem na vida.

Já o terceiro momento, preocupa-se com a definição de crenças que se caracteriza por uma variedade de formas de pensá-las e de investigá-las, seguida por Barcelos (2001).

O estudo das crenças vai além de uma simples descrição, porque procura também contextualizá-las e investigá-las como inseridas em um ambiente (BARCELOS, 2001). Assim, é importante compreendê-las como presentes no processo interativo que ocorre com os alunos e que exercem uma determinada função nas experiências que são construídas dentro da sala de aula. Por isso, pode-se considerá-las como originadas nas experiências de cada indivíduo, socialmente construídas, resultantes da interação do sujeito com o contexto e da sua capacidade de refletir e de pensar sobre o que o cerca (BARCELOS, 2004).

A partir das primeiras situações que o indivíduo tem contato com o processo de ensino/aprendizagem de línguas, as crenças começam a ser construídas. Entende-se que podem ser definidas como compostas por componentes afetivos, cognitivos, interativos e comportamentais que exercem uma constante influência no que o aprendiz sente, sabe e faz. Compreende -se, dessa forma, que é importante que os estudantes tenham a oportunidade e o espaço para tomarem consciência de suas crenças e que consigam, com isso, perceber como elas influenciam no processo de ensino/aprendizagem de uma nova língua estrangeira (LE), não se tornando obstáculos para a aprendizagem. 
Elas são dinâmicas, socialmente construídas e relacionadas à ação de uma maneira indireta e complexa. As crenças sobre o ensino de línguas são o que o sujeito acredita (consciente ou inconscientemente) em relação ao processo de ensino/aprendizagem. Desse modo, tudo o que for resultante da experiência e do estudo do indivíduo, considerando a influência da idade e o contexto de interação, pode ser considerado como crença.

As crenças são construídas socialmente e repercutem nas ações, nas motivações e nas expectativas que o sujeito apresenta para atingir um determinado objetivo. Além disso, podem ser modificadas no decorrer do tempo, pois sofrem alterações a partir das novas experiências vividas relacionadas ao aprendizado de uma LE.

A maior parte das definições sobre crenças consideram o contexto social em que professores e alunos estão inseridos, de forma que as crenças não são estanques, modificando-se de indivíduo para indivíduo. Cada pessoa faz parte de um contexto social, tem sua própria experiência de vida e é influenciada por ela, por isso, as crenças são pessoais, intuitivas e inúmeras vezes, implícitas. Além de serem definidas como conceitos cognitivos, são vistas como interativas e dinâmicas (SILVA, 2010). Nesse sentido, afirma-se que as crenças são individuais e pessoais, mas são influenciadas pelas interações que são estabelecidas no contexto de ensino.

Quanto mais antigas as crenças, mais difícil será para serem modificadas. Essas resistências quanto à modificação ocorrem devido ao caráter afetivo, indicando que foram elaboradas desde cedo pelo indivíduo. Elas definem, de certo modo, as decisões que a pessoa toma durante a vida, organizam suas tarefas e atitudes, fazendo parte da história do sujeito. O contexto mostra-se fundamental, porque não só influencia como também é influenciado nesse processo de ensino/aprendizagem. Isso demonstra que os estudos de crenças estão presentes no contexto de ensino.

\section{METODOLOGIA}

O corpus desta pesquisa é constituído por três dissertações de Mestrado em Estudos Linguísticos, da Universidade Federal de Santa Maria.

Na primeira dissertação, intitulada Crenças sobre ensino/aprendizagem no ensino instrumental de línguas, de autoria de Diniz (2012), a autora objetivou investigar se as crenças de 75 alunos/profissionais, de um curso de capacitação de português língua estrangeira (PLE), para agentes de polícia rodoviária, do governo uruguaio, sofreram 
alterações a partir do ensino instrumental e intensivo. Esse curso foi oferecido pelo Centro de Ensino e Pesquisa de Línguas Estrangeiras Instrumentais (CEPESLI), do Departamento de Letras Estrangeiras Modernas, da UFSM. Para alcançar esse objetivo principal, a autora se baseou nas suas observações durante as aulas e na realização de questionários e entrevistas, no início e final do curso, com a finalidade de averiguar se, após a realização do curso, as crenças iniciais se mantiveram, bem como objetivava analisar contrastivamente as diferenças encontradas nesses dois momentos. Como resultado, a análise dos dados realizada por Diniz (2012) revelou que as crenças, sobre o processo de ensino/aprendizagem, sofreram alterações no decorrer do curso, sendo determinantes para a aprendizagem dos alunos. Também constatou que a abordagem de ensino oferecida aos alunos é fundamental para a constituição de suas crenças com relação ao processo de ensino/aprendizagem.

$\mathrm{Na}$ segunda dissertação, intitulada como A motivação na aula de língua instrumental: crenças de alunos, de autoria de Selvero (2013), a pesquisadora buscou investigar a modificação do Ensino Instrumental nas crenças de alunos e os reflexos dessa modificação na motivação para aprender um novo idioma. A coleta de dados para a pesquisa foi efetuada durante as aulas de duas edições do Curso de Espanhol para Viagens, no CEPESLI, através de pré e pós-questionário, entrevista e observação. A análise de dados revelou que as crenças e a motivação dos alunos influenciaram e sofreram influência do processo de ensino/aprendizagem de espanhol língua estrangeira (ELE) instrumental, de modo que algumas crenças foram ressignificadas e outras acabaram surgindo. No decorrer da análise, foram identificadas crenças relacionadas com a língua espanhola, as quais a consideram uma língua fácil de aprender, pela semelhança com a língua portuguesa. Ao mesmo tempo, os alunos acreditam que essa semelhança pode causar uma desorganização no aprendiz, ou seja, pode confundi-los ainda mais. Com relação à interação, os alunos acreditam que ela favorece o estabelecimento da comunicação entre professor-aluno e aluno-aluno, fator considerado essencial para a aprendizagem de ELE.

$\mathrm{Na}$ terceira dissertação, intitulada Crenças e reflexão de professores sobre a avaliação da aprendizagem no ensino instrumental de línguas estrangeiras, de autoria de Avila (2013), a autora objetivou analisar as crenças de professores sobre a avaliação da aprendizagem em cursos instrumentais de línguas estrangeiras. Os participantes dessa pesquisa foram constituídos por quatro professores que atuaram em cursos de línguas estrangeiras instrumentais, oferecidos pelo CEPESLI. A coleta de dados foi feita 
através de questionário e entrevista com os participantes. A análise revelou que os professores possuem crenças que estão de acordo com o referencial teórico de ensino instrumental e de abordagem comunicativa. No entanto, também apresentam alguns traços de identificação com a abordagem tradicional de ensino de línguas. Com relação à avaliação da aprendizagem, os professores demonstraram crenças condizentes com a modalidade instrumental de ensino de línguas, com traços de avaliação formativa. Os participantes também apresentam características reflexivas.

Primeiramente, para a coleta de dados, mapeou-se, nas três dissertações, as crenças que apareceram sobre material didático, de modo direto ou indireto, no decorrer da pesquisa.

Em seguida, comparou-se os pontos em comum entre os dados encontrados. É importante destacar, que apesar de os trabalhos apresentarem objetivos diferentes, o motivo que levou a escolha dessas três dissertações foi que, primeiramente, as três pesquisas foram realizadas em um mesmo laboratório científico, embasados por um mesmo respaldo teórico e prático, seguindo uma mesma metodologia de ensino instrumental e de abordagem comunicativa de ensino de línguas. Além disso, cabe ressaltar que todos foram orientados pela mesma professora.

\section{CRENÇAS SOBRE O MATERIAL DIDÁTICO DE LÍNGUA ESTRANGEIRA: mapeamento das crenças encontradas nas dissertações analisadas}

$\mathrm{Na}$ primeira dissertação, Crenças sobre ensino/aprendizagem no ensino instrumental de línguas (2012), no pré e pós-questionário, foram detectadas algumas crenças com relação ao material didático.

No questionário, antes do início do curso, com relação às crenças identificadas sobre o processo de ensino/aprendizagem, quando foi perguntando aos informantes dessa pesquisa sobre Quais seriam as características que definem um bom curso de idiomas? A porcentagem de cada característica citada pelos informantes foi de: ênfase no ensino de leitura e escrita (52\%), o professor tem de falar na língua do aluno para dar explicações $(49,3 \%)$, exercícios de tradução $(45,3 \%)$, e utilizar uma atividade que simule uma comunicação real (41,3\%). Desse modo, com base nesses percentuais, Diniz (2012) salienta que as três primeiras características que definem um bom e efetivo curso de língua pertencem ao Método de Gramática-Tradução (GT), de ensino de línguas.

Já no segundo questionário, realizado ao final do curso, quando os informantes foram perguntados novamente sobre quais seriam as características que definem um 
bom curso de idioma, os alunos responderam que as principais características seriam: uso de atividades que simulem uma situação real (76\%); o professor e os alunos devem falar somente em língua estrangeira em aula (69,3\%); ênfase no ensino de leitura e escritura (64\%), e fazer sempre exercícios de tradução $(54,7 \%)$.

Diniz (2012, p.103), ao comparar, essa questão com a aplicada no primeiro questionário, observou que

[...] características pertencentes ao enfoque comunicativo do ensino de línguas (utilização de atividades que simulam uma comunicação real e professor e alunos falar somente no idioma estrangeiro em aula) e que serviram de base ao desenvolvimento do curso, tomaram o lugar de características pertencentes ao Método Gramática-Tradução (GT), [...] como sendo as mais importantes para que um curso de línguas seja considerado bom e efetivo.

De acordo com a autora, entre a realização do pré e pós-questionário, apenas a crença de que a ênfase no ensino de leitura e escrita se manteve entre as primeiras características mais votadas para que um curso de língua seja definido como bom conforme os informantes dessa dissertação. Para a pesquisadora, essa é uma característica relacionada ao método de Gramática e Tradução, onde esse é o foco principal a ser desenvolvido.

Assim, a partir do mapeamento das crenças da primeira dissertação, observamos que, apesar de a proposta desse curso, para agentes de polícia rodoviária uruguaia, apresentar o foco no ensino comunicativo, ainda prevaleceu a crença de que o material didático de um curso de língua, para que seja considerado como eficaz, necessite apresentar exercícios para o desenvolvimento da escrita e aprendizagem de regras gramaticais.

A segunda dissertação, intitulada como A motivação na aula de língua instrumental: crenças de alunos (2013), no pré-questionário e no pós-questionário, Selvero (2013) identificou as seguintes crenças sobre material didático: em uma das perguntas do pré-questionário, Para aprender espanhol é muito importante para você que a aula tenha? O uso do livro didático foi escolhido por oito alunos (50\%). Os aprendizes possuem opiniões diversas sobre o processo de ensino/aprendizagem, de forma que a resposta relacionada com os materiais do curso foi escolhida em um maior número de vezes. Segundo esses estudantes, o material utilizado em aula é um aspecto diferencial para o curso. Desse modo, a crença apresentada por esses aprendizes é que 
para aprender espanhol, o material do curso é muito importante. Já no pósquestionário, essa pergunta foi escolhida por dois estudantes (12,50\%).

A pergunta seguinte foi: $O$ que você considera fundamental em um curso de língua estrangeira para que mantenha o aluno envolvido e motivado? A resposta material didático foi citada por cinco alunos $(31,25 \%)$. No pós-questionário, a mesma pergunta foi escolhida por oito alunos (50\%).

A primeira pergunta analisada no pós-questionário foi: $O$ que poderia ser modificado no curso? A resposta relacionada com o material didático (resposta: mais espaço nas anotações) foi escolhida por dois alunos (12,50\%).

A segunda pergunta analisada do pós-questionário estava diretamente relacionada com a motivação: $O$ que você considera como motivador neste curso? A resposta material didático foi selecionada por quatro alunos (25\%), fortalecendo a importância do material para motivar os estudantes.

As aulas apresentadas no curso foram consideradas dinâmicas; interativas; comunicativas; animadas; motivadoras e interessantes e, assim, verificou-se que, para manter o aluno envolvido e motivado, é importante que exista: material didático; bom preparo dos professores; interesse/necessidade pessoal; dinâmicas realizadas em aula; equipamento de vídeo e áudio; poucos alunos; empatia com os professores; tema do curso e horário. Essas foram as opiniões dos aprendizes que parecem ter agido como um fator diferencial no curso.

Durante a análise, através das opiniões dos estudantes, Selvero (2013) verificou que o material utilizado em aula é um fator diferencial para o processo de ensino/aprendizagem, pois para aprender espanhol o material didático do curso é muito importante, tanto para motivar os alunos quanto para a aprendizagem.

$\mathrm{Na}$ terceira dissertação, intitulada Crenças e reflexão de professores sobre a avaliação da aprendizagem no ensino instrumental de línguas estrangeiras, Avila (2013), ao solicitar para cada um dos participantes que falassem um pouco sobre a importância do Material Didático, nos cursos de língua estrangeira instrumental, ministrados por eles no CEPESLI, identificou a crença unânime entre os professores de que o material didático é imprescindível para os cursos que ministraram. Para eles, o material didático bem planejado e organizado, de acordo com os objetivos de cada curso a ser ministrado, exerce o papel de orientador das ações do professor na sala de aula, servindo como um apoio/guia para o docente. A autora explica que essa crença sobre a importância do material didático se justifica pela experiência desses professores com os 
cursos ministrados no CEPESLI, que estão voltados essencialmente para os objetivos e necessidades dos alunos que fazem os cursos oferecidos pelo centro.

Assim, com base nessa crença identificada pela autora, nota-se a importância do material didático para o sucesso do ensino/aprendizagem, nesse contexto de ensino, evidenciando a necessidade de a elaboração do material estar de acordo com as necessidades/objetivos do público-alvo dos cursos instrumentais.

\section{DISCUSSÃO DOS DADOS}

Tendo como base a análise das três dissertações, na segunda, de Selvero (2013), em que a autora possibilita que os alunos-participantes escolham material didático como possível resposta para várias perguntas do questionário; e na terceira, de Avila (2013), onde a pesquisadora solicita diretamente que os professores falem sobre o material didático do curso que ministraram, observa-se que, de acordo com o objetivo dessas pesquisas, perguntas referentes ao material didático foram realizadas de forma mais direta. No entanto, na primeira, de Diniz (2012), pelo fato de o objetivo ser outro, as crenças encontradas com relação ao material didático foram percebidas de modo mais indireto, sendo possível identificá-las na pergunta do pré e pós-questionário, sobre o que caracterizaria um bom curso para os alunos-informantes.

Contudo, pode-se observar que nas dissertações, mesmo que indiretamente na primeira, o material didático é essencial para a eficácia dos cursos (na visão do professor) e para que o curso seja considerado como bom (na visão dos alunos). Assim, nos três trabalhos, existe a crença de que o material didático é imprescindível, funcionando como um guia para que o professor conduza satisfatoriamente o curso e como instrumento de análise, que deve apresentar determinado tipo de atividades didáticas, como diálogos em LE, para que os participantes o considerem como bom.

Além disso, a partir das crenças sobre interação encontrada nas dissertações, concluiu-se que a interação entre aluno, professor e material didático é determinante para o êxito do curso e para o sucesso do processo de ensino/aprendizagem, já que, segundo os estudantes e professores das pesquisas, a interação favorece $o$ estabelecimento da comunicação essencial para a aprendizagem de língua estrangeira. $\mathrm{Na}$ perspectiva Sociointeracionista, embasamento teórico das dissertações, o estudante aprende em uma cultura e em um contexto, salientando a importância da interação que se estabelece entre os indivíduos. 
Desse modo, nas três dissertações, as crenças dos alunos e professores foram sendo ressignificadas em função das novas experiências que estavam tendo a partir do ensino instrumental, em contraste com as que haviam tido anteriormente. Por isso, não podemos afirmar que as crenças foram modificadas, mas, sim, reavaliadas a partir da metodologia de ensino utilizada. É importante ressaltar que as crenças apresentam dificuldades para serem alteradas, são resistentes, o que não quer dizer que não se modifiquem, mas que mudam ou se alteram com o tempo, e isso se dá em decorrência de um processo contínuo. Como exemplo dessa resistência, podemos citar a crença apresentada pelos participantes nas três dissertações, tanto por alunos como por professores, sobre a importância do ensino de aspectos gramaticais nos cursos.

Para encerrar a pesquisa, pode-se afirmar que as crenças influenciam os comportamentos de cada pessoa, o que leva a pensar que acompanham o ser humano em todas as atividades que exerce em sua vida.

\section{CONSIDERAÇÕES FINAIS}

Nas dissertações, a interação, proporcionada pelo material didático, recebeu uma importância muito evidente no desenvolvimento do processo de ensino/aprendizagem de LE, de forma que, quando trabalhada e estimulada no referido processo, entre professor/aluno/aluno; aluno/aluno; professor/material didático/aluno e material didático/aluno, é fundamental para a comunicação.

De acordo com a perspectiva Sociointeracionista, o aluno aprende inserido na cultura e no contexto; a partir desses elementos, surge a motivação, que denota a participação de vários fatores que determinam o comportamento humano, oferecendo energia e direção para que o estudante cumpra seus objetivos. Com isso, pode-se dizer que a interação teve, portanto, um papel essencial, originando a crença $A$ comunicação se dá pela interação.

O fato de se tratar de cursos, nos quais são priorizados os interesses dos alunos e em que o material didático é elaborado de modo a satisfazer as suas necessidades, favorece a motivação e o envolvimento do estudante. A possibilidade do aprendiz de comunicar-se em LE, faz com que ele se sinta mais independente e capaz de aprender, envolvendo-o mais no processo. Nesse sentido, o material didático deve ser pensado de modo a guiar as necessidades interativas do curso. 
Desse modo, com base nas crenças dos alunos encontradas nas dissertações, podese afirmar que elas são fator determinante para o sucesso do processo de ensino/aprendizagem, em cursos com foco no ensino instrumental e na abordagem comunicativa de ensino de línguas, e que, apesar das diferenças entre os objetivos das dissertações, no perfil dos participantes de cada uma delas e na especificidade dos contextos em que foram coletadas, a importância da interação se repete, sendo fator primordial em todas as três. Por isso, o material didático elaborado para esse tipo de ensino, deve priorizar, essencialmente, a interação proporcionada por atividades didáticas que contemplem a comunicação, dentre elas, essencialmente, os diálogos que abordem assuntos de interesse dos alunos, bem como, o fato de o professor e os alunos somente se comunicarem na língua-alvo.

\section{REFERÊNCIAS}

Almeida Filho, J. C. P. de. (2202). Dimensões comunicativas no ensino de línguas. 3. ed. Campinas: Pontes.

Avila, Andriza Pujol de. (2013). Crenças e reflexão de professores sobre a avaliação da aprendizagem no ensino instrumental de línguas estrangeiras. $2013.134 \mathrm{f}$. Dissertação (Mestrado em Estudos Linguísticos) - Universidade Federal de Santa Maria, Santa Maria - RS.

Barcelos, Ana Maria Ferreira. (2001). Metodologia de Pesquisa das Crenças sobre Aprendizagem de Línguas: Estado da Arte. Revista Brasileira de Linguística Aplicada. Belo Horizonte: Faculdade de Letras da UFMG, v. 1, n. 1, p. 71-93.

(2004). Crenças, Pressupostos e Conhecimentos de Alunos-Professores de Língua Estrangeira e sua Formação Inicial. In: ABRAHÃO, Maria Helena Vieira. Prática de Ensino de Língua Estrangeira: Experiências e Reflexões. Campinas: Pontes, p. 131- 52.

(2007). Reflexões acerca da Mudança de Crenças sobre Ensino e Aprendizagem de Línguas. Rev. Brasileira de Linguística Aplicada, v. 7, n. 2, p. 109 38.

Diniz, Deize Fernandes. (2012). Crenças sobre ensino/aprendizagem no ensino instrumental de línguas. 2012. 161 f. Dissertação (Mestrado em Estudos Linguísticos) Universidade Federal de Santa Maria, Santa Maria - RS.

Coelho, Hilda Simone Henriques. (2005). É possível aprender inglês em escolas públicas? Crenças de professores e alunos sobre o ensino de inglês em escolas públicas. 2005.145 f. Dissertação (Mestrado em Linguística Aplicada) - Universidade Federal de Minas Gerais, Belo Horizonte. 
Selvero, Caroline Mitidieri. (2013). A motivação na aula de língua instrumental: crenças de alunos. 2013. 140 f. Dissertação (Mestrado em Estudos Linguísticos) Universidade Federal de Santa Maria, Santa Maria - RS.

Silva, Kleber Aparecido da. (2007). Crenças sobre o ensino e aprendizagem de línguas na Linguística Aplicada: um panorama histórico dos estudos realizados no contexto brasileiro. Linguagem \& Ensino, v.10, n.1, p. 235-271, jan/jun.

(2010). Crenças no Ensino-Aprendizagem e na Formação de Professores de Línguas: delimitando e atravessando fronteiras na linguística aplicada brasileira. In: p.21-101. (org.) Crenças, Discursos \& Linguagem, 1 v. Campinas, São Paulo: Pontes,

Viana, Wyllds Carraro; CARAZZAI, Marcia Regina Pawlas. (2010). Crenças de professores e alunos a respeito de ensino e aprendizagem de um língua estrangeira. Interfaces, v. 1, n. 1, p. 44-6.

Vilaca, M.L.C. (2012). O material didático no ensino de língua estrangeira: definições, modalidades papéis. $e$ Disponível em: <http://publicacoes.unigranrio.edu.br/index.php/reihm/article/viewFile/653/538>.

Acesso em: 6 jun. 2012

\section{AS AUTORAS}

Emanuele Coimbra Padilha possui graduação em Letras - Licenciatura Plena Habilitação Língua Espanhola e Literaturas pela Universidade Federal de Santa Maria (2010) e especialização em Metodologia do Ensino de Língua Portuguesa e Estrangeira, pela Universidade Internacional de Curitiba/UNINTER (2012). É aluna de Mestrado em Letras, na área de Estudos Linguísticos (UFSM).

E-mail: emanuelecp@ hotmail.com

Caroline Mitidieri Selvero possui graduação em Letras - Licenciatura Plena Habilitação Língua Espanhola pela Universidade Federal de Santa Maria (2007) e em Psicologia (2005), especialista em Gestão Educacional (2010) e Mestrado em Letras, pela mesma instituição, na área de Estudos Linguísticos (2013). Atualmente atua como professora tutora do curso de Letras, habilitação em Língua Espanhola da UFSM, pelo sistema de Ensino a Distância, da Universidade Aberta do Brasil e é professora do SENAC/Santa Maria.

E-mail: caromiti@yahoo.com.br 